\title{
Characterization and complete genome analysis of the surfactin-producing, plant-protecting bacterium Bacillus velezensis 9D-6
}

Elliot Nicholas Grady ${ }^{1,2}$, Jacqueline MacDonald ${ }^{1}$, Margaret T. Ho ${ }^{1}$, Brian Weselowski ${ }^{2}$, Tim McDowell ${ }^{2}$, Ori Solomon ${ }^{1}$, Justin Renaud ${ }^{2}$ and Ze-Chun Yuan ${ }^{1,2^{*}}$ (D)

\begin{abstract}
Background: Bacillus velezensis is an endospore-forming, free-living soil bacterium with potential as a biopesticide against a broad spectrum of microbial pathogens of plants. Its potential for commercial development is enhanced by rapid replication and resistance to adverse environmental conditions, typical of Bacillus species. However, the use of beneficial microbes against phytopathogens has not gained dominance due to limitations that may be overcome with new biopesticidal strains and/or new biological knowledge.

Results: Here, we isolated B. velezensis strain 9D-6 and showed that it inhibits the in vitro growth of prokaryotic and eukaryotic pathogens, including the bacteria Bacillus cereus, Clavibacter michiganensis, Pantoea agglomerans, Ralstonia solanacearum, Xanthomonas campestris, and Xanthomonas euvesicatoria; and the fungi Alternaria solani, Cochliobolus carbonum, Fusarium oxysporum, Fusarium solani, Gibberella pulicaris, Gibberella zeae, Monilinia fructicola, Pyrenochaeta terrestris and Rhizoctonia solani. Antimicrobial compounds with activity against Clavibacter michiganensis were isolated from $B$. velezensis 9D-6 and characterized by high resolution LC-MS/MS, yielding formulae of $\mathrm{C}_{52} \mathrm{H}_{91} \mathrm{~N}_{7} \mathrm{O}_{13}$ and $\mathrm{C}_{53} \mathrm{H}_{93} \mathrm{~N}_{7} \mathrm{O}_{13}$, which correspond to [Leu ${ }^{7}$ ] surfactins $\mathrm{C}_{14}$ and $\mathrm{C}_{15}$ (also called surfactin $\mathrm{B}$ and surfactin $\mathrm{C}$ ), respectively. We further sequenced the $B$. velezensis 9D-6 genome which consists of a single circular chromosome and revealed 13 gene clusters expected to participate in antimicrobial metabolite production, including surfactin and two metabolites that have not typically been found in this species - ladderane and lantipeptide. Despite being unable to inhibit the growth of Pseudomonas syringae DC3000 in an in vitro plate assay, B. velezensis 9D-6 significantly reduced root colonization by DC3000, suggesting that 9D-6 uses methods other than antimicrobials to control phytopathogens in the environment. Finally, using in silico DNA-DNA hybridization (isDDH), we confirm previous findings that many strains currently classified as B. amyloliquefaciens are actually $B$. velezensis.
\end{abstract}

Conclusions: The data presented here suggest $B$. velezensis 9D-6 as a candidate plant growth promoting bacterium (PGPB) and biopesticide, which uses a unique complement of antimicrobials, as well as other mechanisms, to protect plants against phytopathogens. Our results may contribute to future utilization of this strain, and will contribute to a knowledge base that will help to advance the field of microbial biocontrol.

Keywords: Antibacterial, Antifungal, Genome sequencing, Induced systemic resistance (ISR), Plant-microbe interactions, Secondary metabolites

\footnotetext{
* Correspondence: zyuan27@uwo.ca; yuanz@agr.gc.ca

${ }^{1}$ Department of Microbiology \& Immunology, Schulich School of Medicine \&

Dentistry, Dental Science Building Rm. 3014, University of Western Ontario,

London, ON N6A 5C1, Canada

${ }^{2}$ London Research and Development Centre, Agriculture \& Agri-Food

Canada, 1391 Sandford Street, London, ON N5V 4T3, Canada
}

(c) The Author(s). 2019 Open Access This article is distributed under the terms of the Creative Commons Attribution 4.0 International License (http://creativecommons.org/licenses/by/4.0/), which permits unrestricted use, distribution, and reproduction in any medium, provided you give appropriate credit to the original author(s) and the source, provide a link to the Creative Commons license, and indicate if changes were made. The Creative Commons Public Domain Dedication waiver (http://creativecommons.org/publicdomain/zero/1.0/) applies to the data made available in this article, unless otherwise stated. 


\section{Background}

Pathogens of plants are a major constraint to global food production, both in the field and as post-harvest diseases. While synthetic pesticides, including bactericides and fungicides, can be effective, the reliance on synthetic inputs in modern agriculture can cause serious environmental problems by affecting soil fertility, the development of insect resistance, and bioaccumulation of toxic residues in wildlife, livestock, and humans [1]. Such concerns have prompted research into alternative, sustainable strategies to manage plant pests and diseases.

The millions of microbes that live in soil represent a rich source of biodiversity with great potential for the development of biopesticides. Since biopesticides are derived from natural microorganisms, they are often less toxic and affect fewer non-target organisms compared with synthetic pesticides. In addition, they can be effective in small quantities and are biodegradable, largely avoiding pollution problems. Biopesticides are promising in promoting agricultural sustainability and intensification, helping to meet today's complex challenges.

Numerous microorganisms have been successfully developed into biopesticides at the commercial level, most notably strains of Bacillus thuringiensis (Bt) against certain types of insects. However, the use of beneficial microbes has not gained dominance or popularity for control of microbial pathogens, which may partially be due to the inconsistent responses among plant cultivars and field sites [2]. These limitations may be overcome by developing new biopesticidal strains and further research into the biology of plant-microbe and microbe-microbe interactions.

Many of the bacterial antagonists to microbial phytopathogens also belong to the genus Bacillus [3], and the use and number of antagonistically important Bacillus species is increasing very rapidly. Bacillus species synthesize various types of lipopeptide secondary metabolites with specific activities against plant pathogens, including many potent amphiphilic and surfactant lipopeptides comprising bacillomycins, iturins, surfactins, and mycosubtilin [4]. In addition to their broad spectrum of biocontrol ability, Bacillus species replicate rapidly and are resistant to adverse environmental conditions [5].

Bacillus velezensis was originally described in 2005 [6], and various strains have since been researched for their potential as biopesticides [7, 8]. Here we isolated and characterized B. velezensis strain 9D-6 from a farm in Southern Ontario, Canada. This bacterial strain exhibits potent biocontrol activity against a wide range of bacterial and fungal pathogens. We identified antimicrobial compounds produced by B. velezensis 9D-6 as bacterial cyclic lipopeptides [Leu ${ }^{7}$ surfactin $\mathrm{C}_{14}$ and $\left[\mathrm{Leu}^{7}\right]$ surfactin $C_{15}$. We further describe additional plant protection mechanisms of B. velezensis 9D-6 as it reduced root colonization by the plant pathogen Pseudomonas syringae DC3000. Moreover, we sequenced the genome of $B$. velezensis 9D-6 and the complete genome sequence presented here will facilitate future research and development of this and related organisms in agriculture and the biotechnology industry. Overall, the results indicate the potential of developing B. velezensis 9D-6 as a biopesticides for sustainable agriculture.

\section{Results}

Isolation of bacteria with antimicrobial activities

Out of six hundred bacterial isolates from a remediated potato rhizosphere in Norfolk County, Ontario, Canada, isolate 9D-6 exhibited the highest degree of microbial growth inhibition. Zones of microbial inhibition on solid medium around discs inoculated with 9D-6 indicated that it inhibits growth of the Gram positive bacteria $\mathrm{Ba}$ cillus cereus and Clavibacter michiganensis; and of the Gram negative bacteria Pantoea agglomerans, Ralstonia solanacearum, Xanthomonas campestris, and Xanthomonas euvesicatoria; but not Erwinia amylovora or Pseudomonas syringae DC3000. It inhibited growth of the ascomycete fungi Cochliobolus carbonum, Fusarium oxysporum, Fusarium solani, Gibberella pulicaris, Gibberella zeae, Monilinia fructicola, and Pyrenochaeta terrestris; the basidiomycete fungus Rhizoctonia solani; and the deuteromycete fungus Alternaria solani; but not the oomycete Pythium mamillatum. In summary, isolate 9D-6 inhibited growth of six of the seven bacterial pathogens and all nine of the fungal pathogens that were tested (Figs. 1 and 2).

We further tested growth of strain 9D-6 at various temperatures and $\mathrm{pH}$. Strain 9D-6 grew in liquid LB medium at a temperature range of at least between $12^{\circ} \mathrm{C}$ and $50{ }^{\circ} \mathrm{C}$, and at a pH between 5 and 8 , with optimal growth around $30^{\circ} \mathrm{C}$ and $\mathrm{pH} 7$ (Additional files 1 and 2).

\section{B. velezensis 9D-6 phylogeny}

BLASTn analysis of $16 \mathrm{~S}$ rDNA amplified from isolate 9D-6 returned a $>99 \%$ identity match with the reference strain B. velezensis G341. Therefore, isolate 9D-6 is named $B$. velezensis 9D-6.

To estimate the evolutionary position of $B$. velezensis 9D-6 relative to 27 other $B$. velezensis strains for which complete genomes are available, a phylogenetic tree was constructed based on the RNA polymerase $\beta$ subunit $(r p o B)$ gene. Compared with the 16S rRNA gene, rpoB provides better resolution between closely related organisms [9]. The phylogenetic analysis suggests that B. velezensis 9D-6 is most closely related to B. velezensis AS43.3, and is also closely related to B. velezensis strains CC09, SB1216, TrigoCor1448, UCMB5033, and UCMB5036, followed together by UCMB5113 and the reference strain G341 (Fig. 3). 


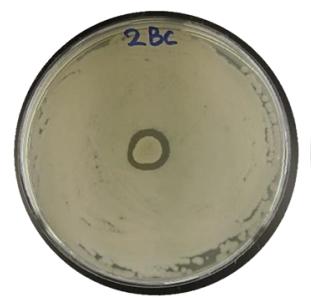

Inhibition: + Bacillus cereus Gram positive

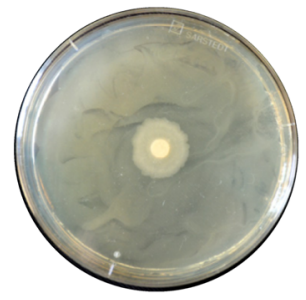

Inhibition: Pseudomonas syringae Gram negative

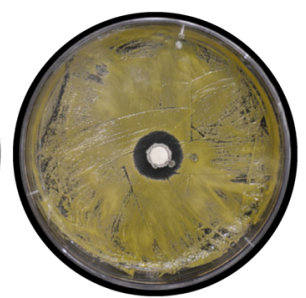

Inhibition: ++ Clavibacter michiganensis Gram positive

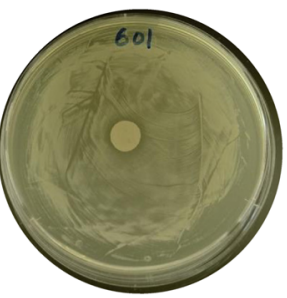

Inhibition: + Ralstonia solancearum Gram negative

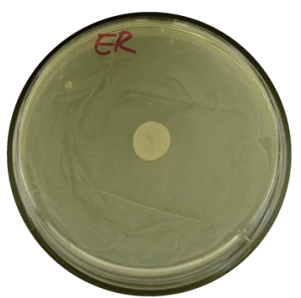

Inhibition: Erwinia amylovora Gram negative

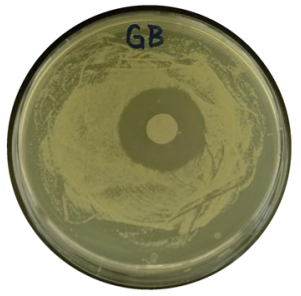

Inhibition: +++ Xanthomonas campestris Gram negative

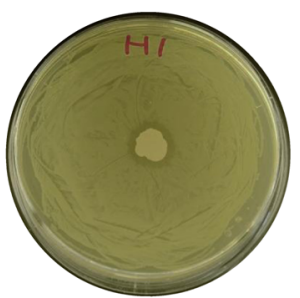

Inhibition: + Pantoea agglomerans Gram negative

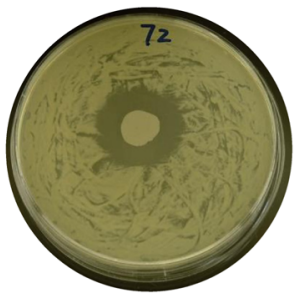

Inhibition: +++

Xanthomonas euvesicatoria Gram negative

Fig. 1 Inhibition of bacterial pathogens by B. velezensis 9D-6 in in vitro plate assays. Representative plates are shown, along with average degree of inhibition zone of clearance measurements: $(-)=$ no inhibition, $(+)=0.1-1.9 \mathrm{~mm},(++)=2.0-4.9 \mathrm{~mm},(+++)=5.0-9.9 \mathrm{~mm},(++++) 10.0 \mathrm{~mm}+$. $B$. cereus causes necrotic enteritis of mammals, including humans [52]; C. michiganensis causes bacterial canker of tomato [10]; E. amylovora causes fire blight of apple and pear [53]; P. agglomerans causes several diseases of several crops [54]; P. syringae DC3000 causes bacterial speck of tomato, Arabidopsis, and Nicotiana benthamiana [55]; $R$. solanacearum causes several diseases of several crops [56]; $X$. campestris causes black rot of the Brassicaceae family (including broccoli and radish) [57]; X. euvesicatoria causes bacterial spot of tomato [58]

In silico DNA-DNA hybridization (isDDH) was performed to confirm 9D-6 as a member of B. velezensis and to validate its position in the phylogenetic tree. Of the strains included in the tree (Fig. 3), the highest isDDH values with the genome of $B$. velezensis $9 D-6$ were $o b$ tained for strains TrigoCor1448 (92.5\%), AS43.3 (92.0\%), UCMB5113 (91.7\%), G341 (91.7\%), UCMB5033 (91.2\%), SB1216 (91.1\%), UCMB5036 (89.3\%), and CC09 (89.1\%). These eight strains form a cluster with $B$. velezensis 9D-6 in the $r p o B$ phylogenetic tree. The values for isDDH between $B$. velezensis 9D-6 and that of the other $B$. velezensis strains range from 79 to $86 \%$. In contrast, the value for is DDH is $21 \%$ between B. velezensis 9D-6 and B. subtilis subtilis 168. However, it ranges between 55 and $92 \%$ between B. velezensis 9D-6 and 22 B. amyloliquefaciens strains with complete genomes: 15 of these values are between 79 and $92 \%$, while the remaining six (including the type strain DSM 7) are between 55 and 56\%.

\section{B. velezensis $9 \mathrm{D}-6$ produces antimicrobial compounds} [Leu ${ }^{7}$ ] surfactin $\mathrm{C}_{14}$ and $\left[\right.$ Leu $\left.^{7}\right]$ surfactin $\mathrm{C}_{15}$

To identify the antimicrobial compounds that contribute to biocontrol, B. velezensis 9D-6 metabolites were isolated into fractions using liquid chromatography, and each fraction was tested for antibacterial activity against the Gram-positive bacterium C. michiganensis, chosen due to its rapid growth rate and agricultural relevance $[10,11]$. A fraction demonstrating activity (Fig. 4a) was then subjected to LC-MS to identify the active compound.

The two major peaks observed had predicted chemical formulas of $\mathrm{C}_{52} \mathrm{H}_{91} \mathrm{~N}_{7} \mathrm{O}_{13}$, and $\mathrm{C}_{53} \mathrm{H}_{93} \mathrm{~N}_{7} \mathrm{O}_{13}$. Antibase identified the lipopeptide surfactins as possible identifications. Comparison of the MS/MS of compound $\mathrm{C}_{52} \mathrm{H}_{91} \mathrm{~N}_{7} \mathrm{O}_{13}$ with previously published MS/MS spectra [12] identified this peak as $\left[\mathrm{Leu}^{7}\right]$ surfactin $\mathrm{C}_{14}$ (sometimes called surfactin B). MS/MS of the peak $\mathrm{C}_{53} \mathrm{H}_{93} \mathrm{~N}_{7} \mathrm{O}_{13}$ allowed partial amino acid sequence to be determined by de novo sequencing (Fig. 5), suggesting it is [ Leu $\left.^{7}\right]$ surfactin $C_{15}$ (sometimes called surfactin C).

The surfactin fraction was then tested against the Gram-negative bacterium P. syringae DC3000 and the ascomycete fungus C. carbonum for verification (Fig. 4b-c). The antimicrobial disc inhibited C. carbonum when inoculated with surfactin concentrations between $1 \mathrm{mg} / \mathrm{mL}$ and $10 \mathrm{mg} / \mathrm{mL}$. However, for P. syringae DC3000, the zones of inhibition were only apparent at the higher concentrations $(5 \mathrm{mg} / \mathrm{mL}$ and $10 \mathrm{mg} / \mathrm{mL})$ and were not very large, consistent with the inability of live B. velezensis to antagonize this bacterium (Fig. 1).

\section{B. velezensis $9 \mathrm{D}-6$ reduces the attachment and infection of Arabidopsis by $P$. syringae DC3000}

To determine whether B. velezensis 9D-6 is able to inhibit microbial phytopathogenesis by mechanisms other 


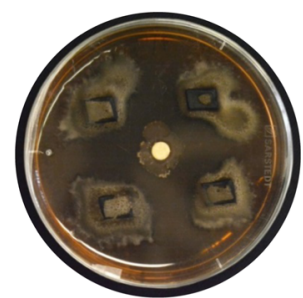

Inhibition: +++ Cochliobolus carbonum Fungus, Ascomycete

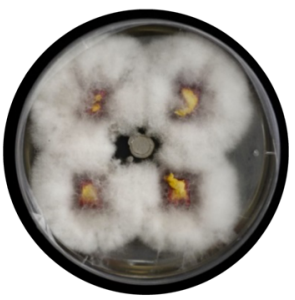

Inhibition: ++ Gibberella zeae Fungus, Ascomycete

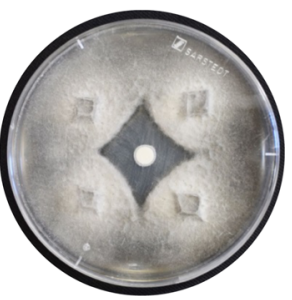

Inhibition: +++ Alternaria solan Fungus, Deuteromycete

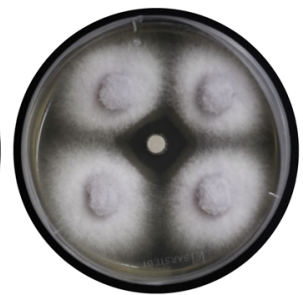

Inhibition: ++ Fusarium oxysporum Fungus, Ascomycete

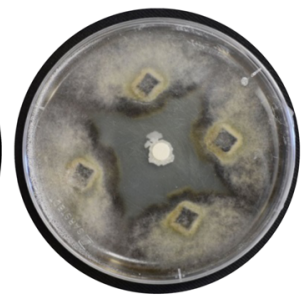

Inhibition: ++++ Monilinia fructicola Fungus, Ascomycete

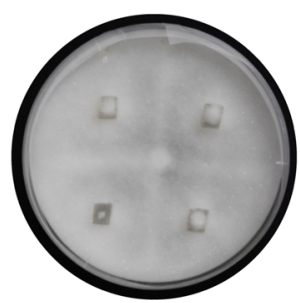

Inhibition: -

Pythium mamillatum

Oomycete

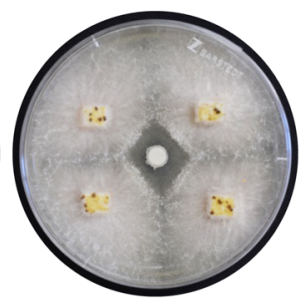

Inhibition: ++ Fusarium solani Fungus, Ascomycete

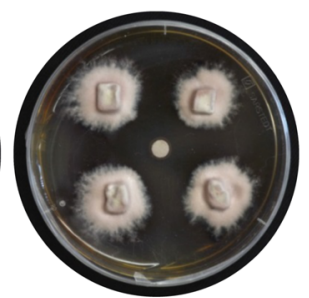

Inhibition: +++ Pyrenochaeta terrestris Fungus, Ascomycete

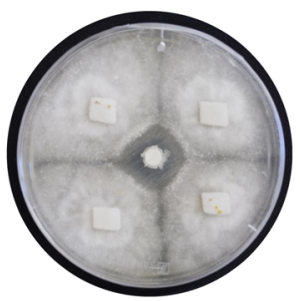

Inhibition: ++ Gibberella pulicaris Fungus, Ascomycete

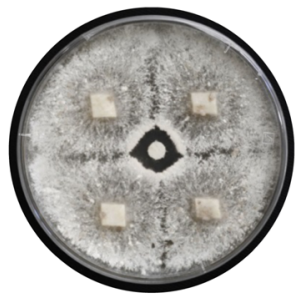

Inhibition: ++ Rhizoctonia solani Fungus, Basidiomycete

Fig. 2 Inhibition of eukaryotic pathogens by B. velezensis 9D-6 in in vitro plate assays. Representative plates are shown, along with average degree of inhibition zone of clearance measurements: $(-)=$ no inhibition, $(+)=0.1-1.9 \mathrm{~mm},(++)=2.0-4.9 \mathrm{~mm},(+++)=5.0-9.9 \mathrm{~mm},(++++) 10.0$ $\mathrm{mm}+$. C. carbonum causes Northern leaf spot and ear rot of sorghum, corn, apple, and peach [59]; F. oxysporum causes wilt and root rot of several crops [60]; F. solani causes mycotic keratitis of mammals (including humans) and root rot of plants [61]; G. pulicaris causes potato dry rot [62]; G. zeae causes wheat head blight and maize ear rot [63]; M. fructicola causes brown rot of nectarine and other stone fruit [64]; P. terrestris causes pink rot of onion [65]; $R$. solani causes several diseases of several crops [66]; A. solani causes early blight of tomato and potato [67]; $P$. mamillatum causes damping off and root rot of sevral crops $[68,69]$

than antimicrobial production, we tested its ability to reduce root colonization by $P$. syringae DC3000, a Gram-negative bacterium. Since growth of $P$. syringae DC3000 was not inhibited by B. velezensis 9D-6 in the in vitro plate assay (Fig. 1), reduced root colonization in response to $B$. velezensis 9D-6 should be due to a mechanism other than production of bacteriocidal or bacteriostatic antimicrobials.

Co-inoculation of $A$. thaliana seedlings with $B$. velezensis 9D-6 and $P$. syringae DC3000 produced milder disease symptoms compared to inoculation with $P$. syringae DC3000 alone. By contrast, B. velezensis 9D-6 alone produced no visible symptoms of disease (Fig. 6). Co-inoculation of $A$. thaliana seedlings with $B$. velezensis 9D-6 and RFP-labeled P. syringae DC3000 also resulted in a notable decrease in root colonization by the pathogen at all tested concentrations, as indicated by an observable decrease in RFP fluorescence (Fig. 7).

\section{The $B$. velezensis 9D-6 genome sequencing and analysis}

To allow further investigation into the biocontrol mechanisms of B. velezensis 9D-6 and its application for sustainable agriculture, we determined its complete genome.

The B. velezensis 9D-6 genome consists of a single $3.96 \mathrm{Mb}$ circular chromosome (Fig. 8), which fits within the range of 3.81 to $4.24 \mathrm{Mb}$ reported for other completed genomes of the species. Like nearly $80 \%$ of those strains, it does not harbor a plasmid. The B. velezensis 9D-6 genome is predicted to include 3942 total genes, of which 3849 (97.6\%) are protein coding genes, 93 (2.4\%) 


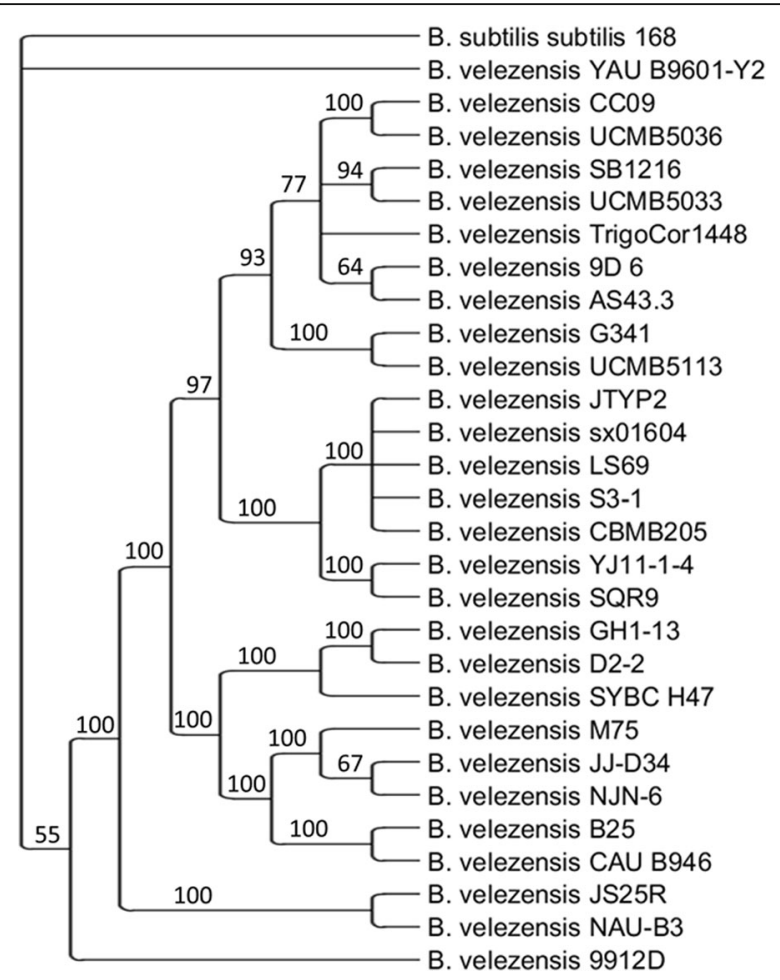

Fig. 3 Majority-rule consensus tree of rpo genes rooted with B. subtilis subtilis 168 as the outgroup. Bayesian clade credibility values are indicated at nodes. GenBank acession numbers are listed in brackets: B. subtilis subtilis strain 168 (CP01 0052), B. velezensis strains 9912D (CP017775), 9D-6 (CP020805), AS43.3 (CP003838), B25 (LN999829), CAU B946 (HE617159), CBMB205 (CP01 1937 and CP014838), CC09 (CP015443), D2-2 (CP014990), G341 (CP011686), GH1-13(CP019040), JJ-D34 (CP011346), JS25R (CP009679), JTYP2 (CP020375), LS69 (CP015911), M75 (CP016395), NAU-B3 (HG514499), NJN-6 (CP007165), S3-1 (CP016371), SB1216 (CP015417), SQR9 (CP006890), SYBC H47 (NZ_CP017747), s×01604 (CP018007),

TrigoCor1448 (CP007244), UCMB5033 (HG328253), UCMB5036 (HF563562), UCMB5113 (HG328254), YAU B9601-Y2 (HE774679), YJ11-1-4 (CP011347)

are RNA coding, and $82(2.1 \%)$ are pseudogenes (Additional file 3). Of the RNA coding genes, 21 are predicted to code rRNA and 68 are predicted to encode tRNA. Among the predicted genes, 2736 (69.4\%) are associated with general COG function categories. The distribution of genes in these categories is presented in Additional file 4.

A core genome containing 2574 coding sequences is shared among $B$. velezensis, the closely related species Bacillus amyloliquefaciens, and B. subtilis subtilis 168 [13]. Among B. velezensis strains with completed genomes, the number of coding sequences is typically between 3600 and 4000 (with a clear outlier of 4411 for B. velezensis SRCM101413) and the number for B. velezensis 9D-6 fits within this expected range. Similarly, the $46.4 \%$ GC content of B. velezensis 9D-6 is comparable to the other completed $B$. velezensis genomes, which range from 45.9 to $46.8 \% \mathrm{GC}$. The 9D-6 genome sequence was deposited in GenBank (CP020805): https://www.ncbi.nl m.nih.gov/nuccore/CP020805
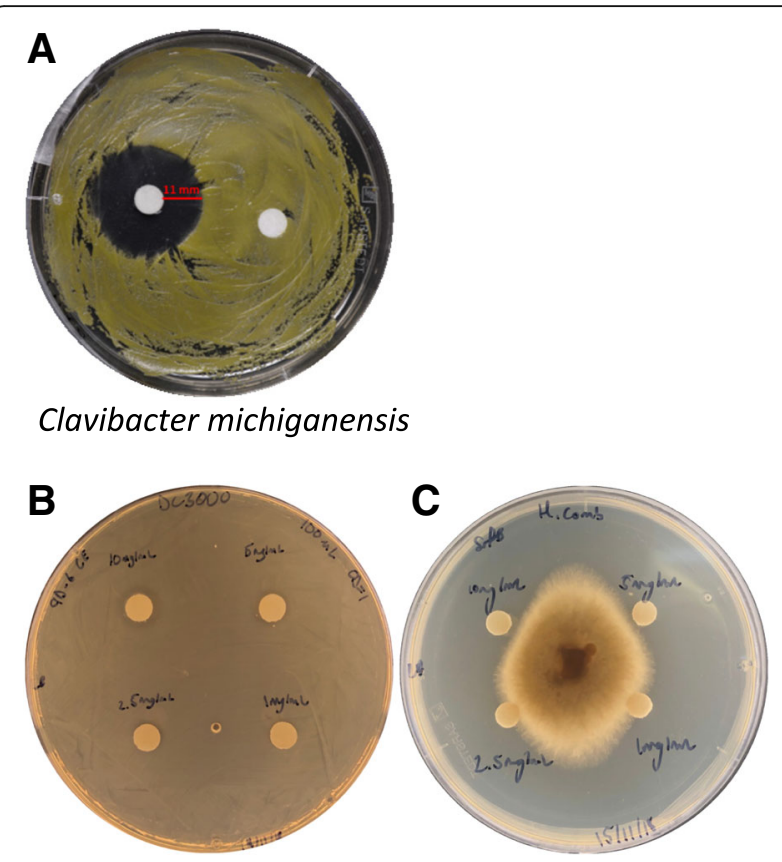

Pseudomonas syringae

Cochliobolus carbonum

Fig. 4 Metabolite fraction from $B$. velezensis liquid culture demonstrates antimicrobial activity. $\mathbf{a}$ The antimicrobial disc (left) was prepared by adding $50 \mu \mathrm{L}$ of fraction to filter paper, and placed onto an LB agar plate spread with C. michiganensis. The control disc (right) used acetonitrile in place of the metabolite fraction. $\mathbf{b}$ Antimicrobial discs with surfactin concentrations between $1 \mathrm{mg} / \mathrm{mL}$ and $10 \mathrm{mg} / \mathrm{mL}$ were placed onto an LB agar plate spread with P. syringae DC3000. c Antimicrobial discs with surfactin concentrations between $1 \mathrm{mg} / \mathrm{mL}$ and $10 \mathrm{mg} / \mathrm{mL}$ were placed onto an LB agar containing a central agar plug of C. carbonum

\section{Special genomic features}

The B. velezensis 9D-6 genome is predicted to contain thirteen gene clusters involved in antimicrobial production (Table 1), most of which are conserved in all B. velezensis strains (bacilysin, surfactin, macrolactin, fengycin, bacillaene, difficidin, bacillibactin [7, 13], butirosin, and a terpene [13]). AntiSMASH analysis of the $B$. velezensis 9D-6 genomic surfactin cluster predicted a lipopeptide sequence of ELLVDLL, consistent with the peptide ring of surfactin determined by the LC-MS/MS and de novo peptide sequencing. In contrast, the clusters predicted to produce ladderane and lantipeptide have not typically been found in this species. The lantipeptide cluster contains a predicted set of ten core biosynthetic genes, including the crucial modification enzyme LanM, but does not contain obvious hits for some other components including LanA and LanT. The ladderane cluster contains four core biosynthetic genes, encoding an acyl carrier protein, beta-ketoacyl synthase, 3-oxoacyl-ACP synthase, and 3-oxoacyl-ACP reductase.

To determine the prevalence of the lantipeptide and ladderane clusters among strains of $B$. velezensis, we search the 27 other strains that are represented in our 


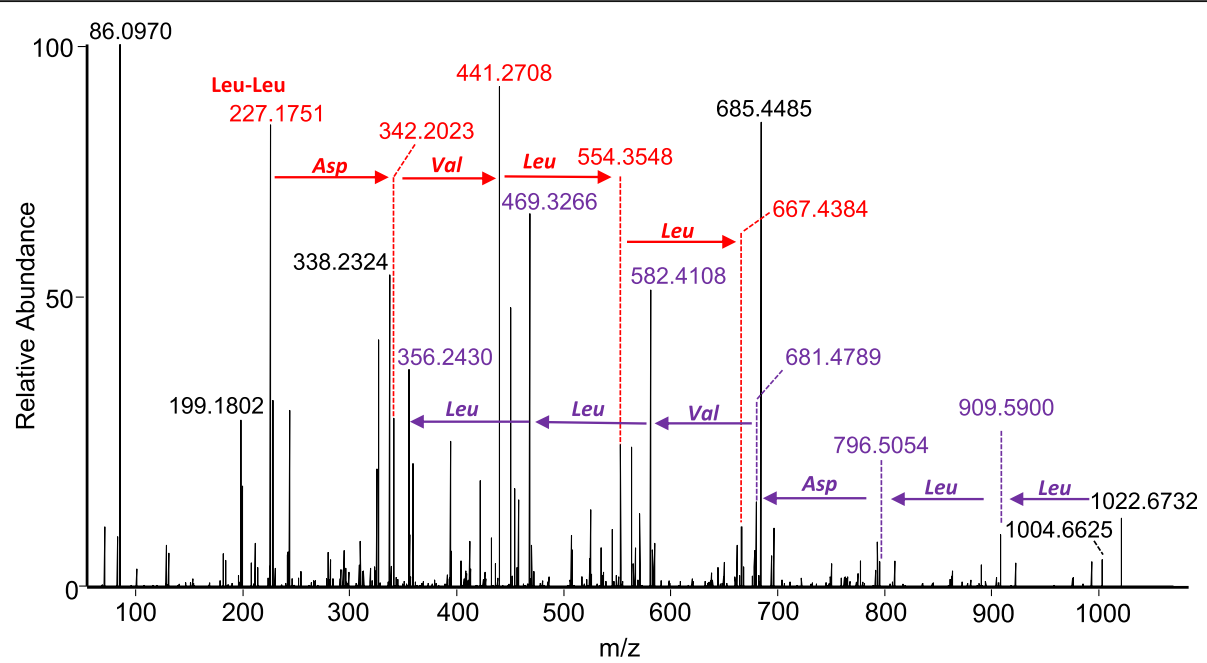

Fig. $5 \mathrm{MS} / \mathrm{MS}$ de novo sequencing identified $\mathrm{m} / \mathrm{z} 1022.6732\left(\mathrm{C}_{53} \mathrm{H}_{93} \mathrm{~N}_{7} \mathrm{O}_{13}\right)$ as [Leu ${ }^{7}$ s surfactin $\mathrm{C}_{15}$. Purple arrows show changes in fragment $\mathrm{m} / \mathrm{z}$ due to loss of the indicated amino acids from the full-length molecule. Red arrows show changes in fragment $\mathrm{m} / \mathrm{z}$ due to addition of the indicated amino acids, starting from the di-leucine fragment at $\mathrm{m} / \mathrm{z} 227.1751$

phylogenetic tree, all of which have completed genomes. Clusters for lantipeptides were found in 13 of the 27 other strains, while clusters for ladderane were found in only 2 of the 27 other strains. One strain other than 9D-6 harbors clusters for both lantipeptide and ladderane (strain UCMB5113). Of interest, other uncommon clusters among the strains are for thiopeptide (in 4 strains: D2-2, M75, JJ-D34, and B25) and phosphonate (in 3 strains: YAU B9601-Y2, JS25R, and NAU-B3) (Table 2). Consistent with previous findings, little correlation was observed between the presence of any specific cluster and its phylogenetic position within the species. B. velezensis SRCM101413, the strain with the largest number of coding sequences, contains a cluster for ladderane, but not for lantipeptide, thiopeptide, nor phosphonate.

Manual mining of B. velezensis 9D-6 also identified a gene for butanediol dehydrogenase and genes predicted to encode components of secretion systems including the inner-membrane spanning twin-arginine translocation
(Tat) system, SecYEG translocon, and the Type VII/ESX secretion system.

\section{Discussion}

The isolate 9D-6 was named B. velezensis 9D-6 based on a $>99 \% 16 \mathrm{~S}$ rDNA identity match with the reference strain $B$. velezensis G341. In silico DNA-DNA hybridization (isDDH) also confirmed 9D-6 as a member of $B$. velezensis, with the isDDH value between $B$. velezensis 9D-6 and other $B$. velezensis strains ranging from 79 to $92 \%$. This is above the typical standard of $70 \%$ for delineating species. Comparing B. velezensis 9D-6 to members of the related $B$. amyloliquefaciens gave is DDH values between 55 and 92\%, with no values between 57 and $78 \%$, in support of previous findings that many strains currently classified as B. amyloliquefaciens are actually B. velezensis [14].

A key distinguishing feature among strains of $B$. velezensis is the complement of secondary metabolite clusters that are predicted contributors to antimicrobial

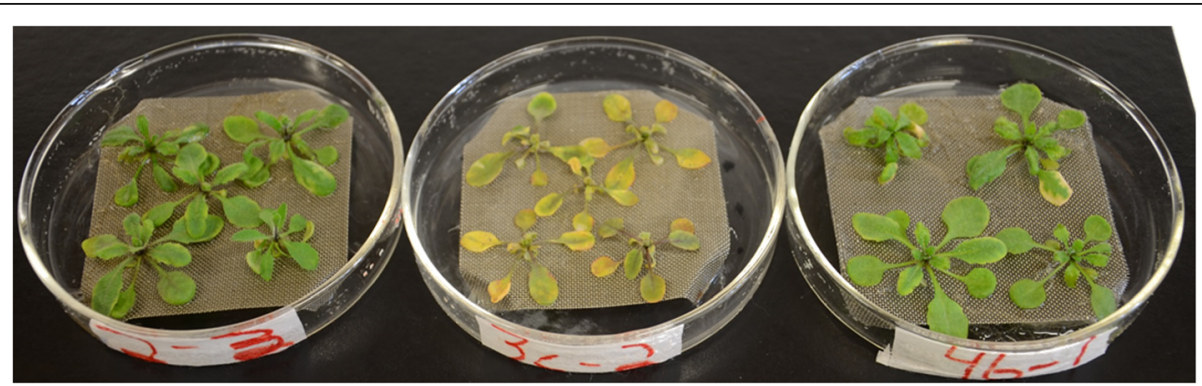

Fig. 6 Effect of B. velezensis 9D-6 co-inoculation with P. syringae DC3000 on A. thaliana disease symptoms. A. thaliana seedlings were cultured in hydroponic medium for seven days with B. velezensis 9D-6 alone (left), P. syringae DC3000 alone (middle), or both B. velezensis 9D-6 and P. syringae DC3000 (right). Representative samples are shown 


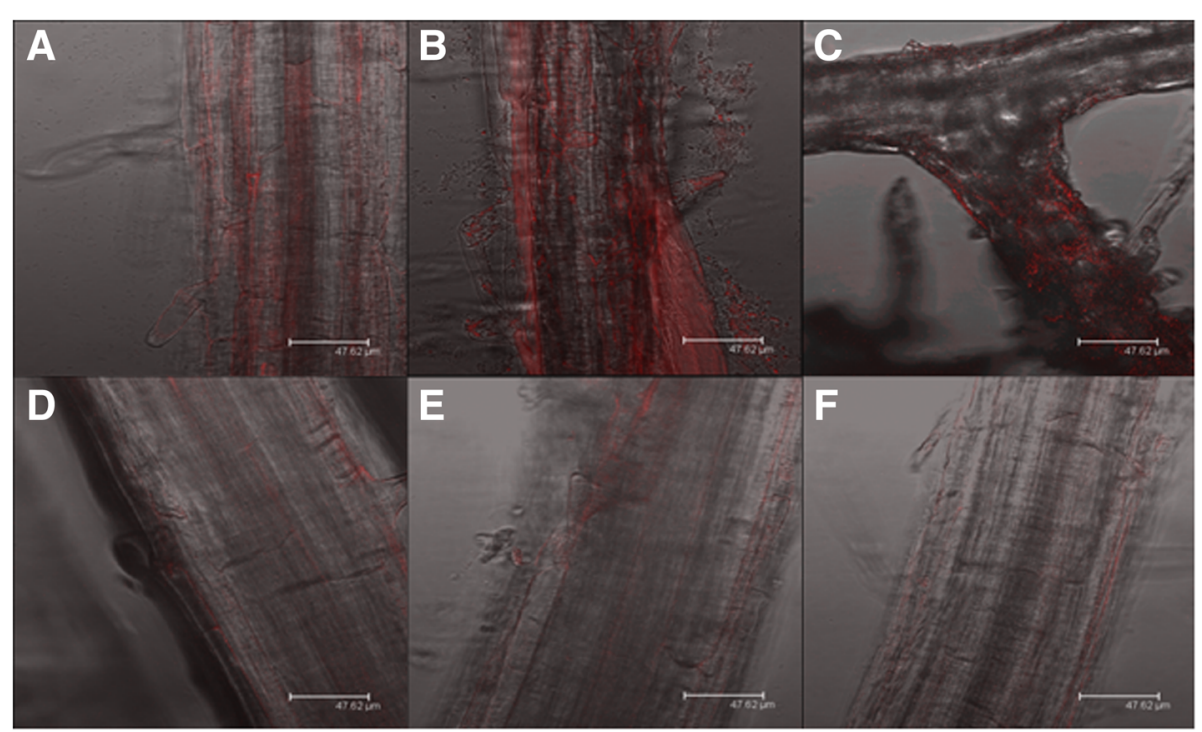

Fig. 7 Effect of B. velezensis 9D-6 co-inoculation on P. syringae DC3000 root colonization. A. thaliana seedlings were cultured in hydroponic medium for seven days with RFP-labeled P. syringae DC3000 alone at $2.5 \times 10^{5} \mathrm{CFU} / \mathrm{mL}, 2.5 \times 104 \mathrm{CFU} / \mathrm{mL}$, or $2.5 \times 10^{3} \mathrm{CFU} / \mathrm{mL}$ (A-C respectively), or with both B. velezensis 9D-6 at $2.5 \times 10^{5} \mathrm{CFU} / \mathrm{mL}$ and P. syringae DC3000 at $2.5 \times 10^{5} \mathrm{CFU} / \mathrm{mL}, 2.5 \times 10^{4} \mathrm{CFU} / \mathrm{mL}$, or $2.5 \times 10^{3} \mathrm{CFU} / \mathrm{mL}$ (D-F respectively). Roots were imaged using confocal microscopy to detect red fluorescence indicative of $P$. syringae DC3000 attachment. Representative samples are shown

activities [7]. While many such clusters are common to multiple species of Bacillus, others are specific to certain strains of $B$. velezensis, with little correlation to the predicted phylogenetic relationships among these strains $[7,13]$. Such ancillary clusters may function primarily to control other Bacillus species and Gram-positive bacteria [7].

The B. velezensis 9D- 6 genome is predicted to contain thirteen antimicrobial gene clusters. While the majority of the thirteen are conserved in all B. velezensis strains, the clusters predicted to produce ladderane and lantipeptide have not typically been found in this species. The cluster for ladderane has previously been found in Bacillus strains isolated from marine sponges [15], while various Bacillus strains produce lantipeptides [16].

Lantipeptides are ribosomally synthesized peptides that are extensively post-translationally modified, and often disrupt the integrity of Gram-positive bacterial cell walls. For a class II lantipeptide, which was predicted for B. velezensis 9D-6, the ribosomally produced precursor peptide, LanA, is processed by two conserved enzymes, LanM and LanT. LanM acts via an N-terminal dehydratase domain and a C-terminal cyclase domain, whereas LanT performs cleavage of the leader peptide. Additional post-translational modifications can be performed by other enzymes, leading to further structural diversity among lantipeptides [17]. While the B. velezensis 9D-6 cluster contains a gene for LanM, obvious matches for LanA and LanT appear to be absent, raising the possibility of a pseudogene cluster or misidentification.

Ladderanes are a type of lipid known to be present in membranes that surround anammoxosomes, which are involved in anaerobic ammonium oxidation by bacteria in the phylum Planctomyces. While gene clusters for ladderane biosynthesis have been identified, the precise biosynthetic pathway is still unknown [18] leaving a greater possibility for misidentification of this cluster. In fact, a large overlap has been found between gene clusters for ladderane synthesis and those for synthesis of aryl polyenes [19], which offer protection from reactive oxygen species [20]. Aryl polyene gene clusters have been found mainly in Gram-negative bacteria, many of which are either commensals or pathogens of eukaryotes. Their phylogenetic distribution has been described as markedly discontinuous, with clusters present in some strains but not others of most genera [19]. This last point is consistent with our finding of the ladderane gene cluster in B. velezensis 9D-6 but not in most of the other $B$. velezensis strains.

The genome of $B$. velezensis 9D-6 also encodes a putative butanediol dehydrogenase, which is a critical enzyme in the production of butanediol, known to induced systemic resistance (ISR) in plants [21]. The presence of this gene therefore suggests that $B$. velezensis 9D-6 may contribute to plant defenses via ISR, whereby plants are primed for faster and stronger defenses against pathogens.

Additionally present are genes predicted to encode components of secretion systems, which may help mediate relationships between $B$. velezensis 9D-6 and other organisms, including plants and pathogenic microbes. Among these are components of the inner-membrane spanning twin-arginine translocation (Tat) system and 


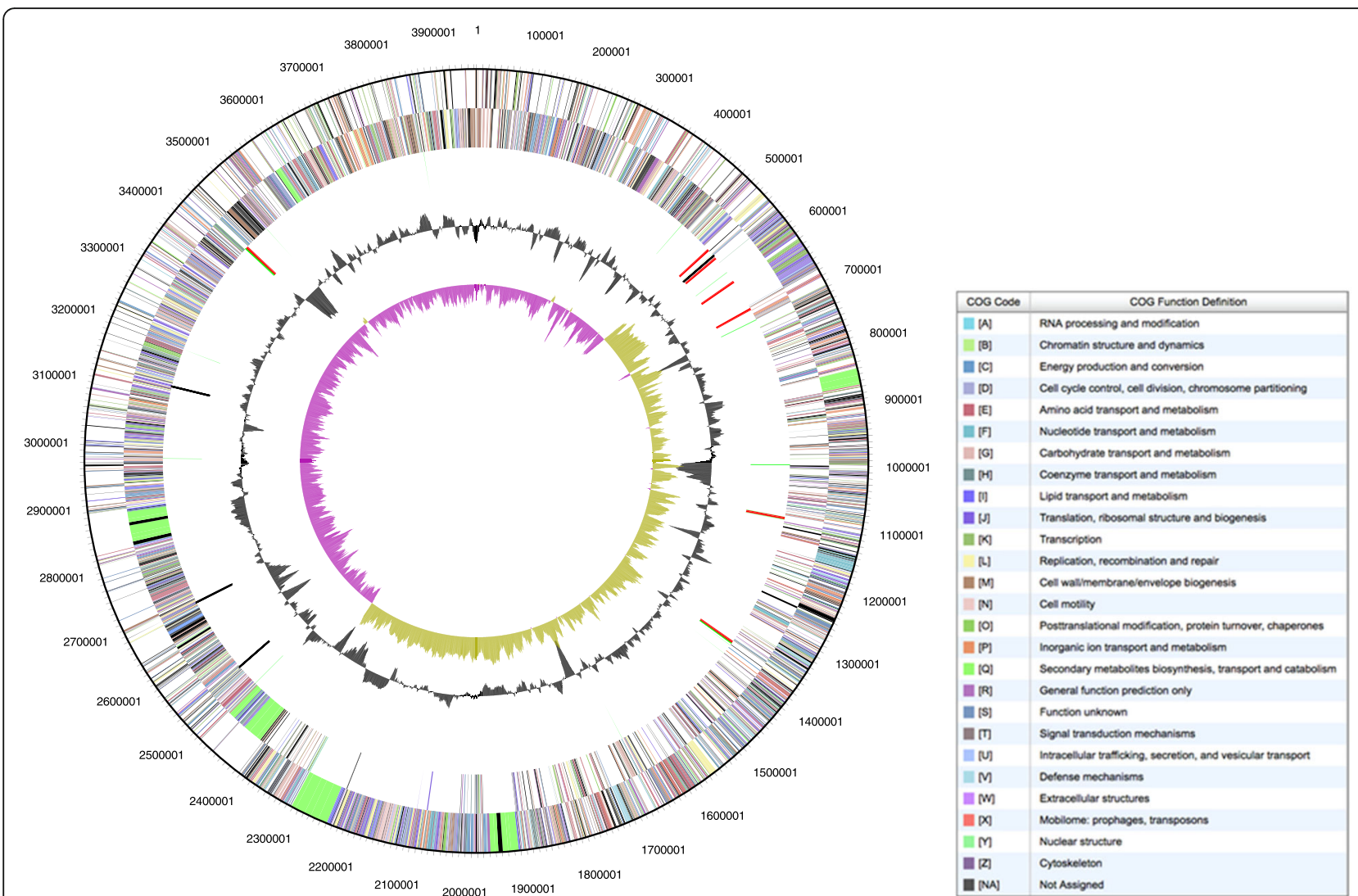

Fig. 8 Visual representation of the B. velezensis 9D-6 genome From outer to inner rings: forward coding DNA sequence genes coded to COG functions, reverse coding DNA sequence genes coded to COG functions, RNAs (tRNAs in green, rRNAs in red, and other RNAs in black), GC content (black), and GC skew (magenta and yellow). Map was generated from the Joint Genome's Institute (JGI) Integrated Microbial Genomics (IMG) Database [48]

SecYEG translocon, and the Type VII/ESX secretion system, whose function remains unknown. The twin-arginine translocation (Tat) system transports fully folded proteins to the cell envelope or extracellular space [22], while the SecYEG translocon participates in the insertion of membrane proteins [23].

B. velezensis 9D-6 inhibited in vitro growth of six of the seven bacterial pathogens and all nine of the fungal pathogens that were tested. This activity was shown to be due in part to the active compounds $\left[\mathrm{Leu}^{7}\right]$ surfactin $\mathrm{C}_{14}$ (sometimes called surfactin $\mathrm{B}$ ) and $\left[\mathrm{Leu}^{7}\right]$ surfactin $\mathrm{C}_{15}$ (sometimes called surfactin $\mathrm{C}$ ). These surfactins were shown to be inhibitory to the bacterial phytopathogen $C$. michiganensis and the ascomycete fungus $C$. carbonum, but not to $P$. syringae DC3000, consistent with the inability of live $B$. velezensis to antagonize this latter bacterium. Since not all test organisms used for the live $B$. velezensis disc assays were tested with surfactin, this antimicrobial fraction does not necessarily contribute to the activity against all of these organisms.

Surfactins are cyclic lipopeptides, each comprised of seven amino acids and a hydrophobic fatty acid chain that is at least thirteen carbons long. They are synthesized independently of messenger RNA by nonribosomal peptide synthetases (NRPSs), which are multienzyme complexes that can incorporate a mixture of D- and L-amino acids. While structures have been identified that vary in amino acid identity at the 7th position, those that retain the ELLVDLL sequence have variously been called [Leu]- or $\left[\mathrm{Leu}^{7}\right]$ surfactin $[24,25]$, surfactin A (where isoforms with $\mathrm{V}$ and $\mathrm{I}$ at position 7 are called surfactin $B$ and $C$, respectively $[26,27]$, or simply surfactin; while the nature of the acyl chain is designated as $\mathrm{C}_{13}$, $\mathrm{C}_{14}, \mathrm{C}_{15}$, etc. (sometimes called surfactin $\mathrm{A}, \mathrm{B}, \mathrm{C}$, etc. [28], which can be a source of confusion since the same nomenclature is used for the isoforms with respect to amino acid identity at position 7).

Surfactins are known to have antimicrobial properties that act against both bacteria and fungi [29]. They can insert into bacterial cell membranes, solubilizing the fluid phospholipid bilayer and creating pores and ion channels $[29,30]$. Surfactins have also been shown to interfere with protein processing and secretion. For example, they disrupt aerial development of Streptomyces 
Table 1 Antimicrobial gene clusters present in B. velezensis 9D-6

\begin{tabular}{lll}
\hline Predicted product & Enzyme complex & Genome location \\
\hline Bacilysin & & $174,243-215,661$ \\
Surfactin (cyclic lipopeptide) & nrps & $820,469-885,876$ \\
Ladderane & & $1,177,384-1,218,583$ \\
Butirosin & t2pks & $1,451,008-1,492,252$ \\
Terpene & & $1,575,053-1,595,793$ \\
Lantipeptide & & $1,714,976-1,743,864$ \\
Macrolactin (polyketide) & transatpks & $1,893,381-1,979,274$ \\
Bacillaene (polyketide) & transatpks; nrps & $2,209,276-2,311,962$ \\
Fengycin (bacteriocin) & transatpks; nrps & $2,364,456-2,489,567$ \\
Terpene & & $2,517,434-2,539,317$ \\
Unknown & t3pks & $2,602,290-2,643,390$ \\
Difficidin (polyketide) & transatpks & $2,801,002-2,901,455$ \\
Bacillibactin (bacteriocin) & nrps & $3,562,018-3,628,825$ \\
\hline
\end{tabular}

by interfering with the peptide SapB [31]. For antifungal activity, surfactins can inhibit glucan synthase, which is involved in cell wall synthesis, and can induce apoptotic markers [30]. In addition, surfactins are thought to play a key role in triggering ISR [32]. They may also contribute to swarming motility [33, 34], which can help achieve effective rhizosphere colonization and facilitate plant growth promoting traits while simultaneously inhibiting competing microorganisms via antimicrobial activity [34].

Despite the inability of either live B. velezensis 9D-6 or its surfactins to inhibit growth of $P$. syringae DC3000 in plate assays, $B$. velezensis 9D-6 proved effective against this phytopathogen in a plant system. It reduced both observable symptoms of $P$. syringae DC3000 in plants, as well as $P$. syringae DC3000 colonization of plant roots. These results indicate that $B$. velezensis $9 \mathrm{D}-6$ produces a biocontrol effect attributable to something other than bacteriostatic or bactericidal compounds. Such biocontrol mechanisms could include adverse effects of sub-inhibitory concentrations of antimicrobials, which may possibly include surfactins. For example, secondary metabolites or enzymes can derail normal signaling pathways in other bacteria, including those leading to biofilm formation [31], which may be important to $P$. syringae DC3000's survival or adhesion on plant roots but not on solid laboratory medium. Alternatively, $B$. velezensis 9D-6 may otherwise outcompete $P$. syringae DC3000 for resources that are more limiting in the plant system compared to the nutrient plate, or more limiting specifically within a biofilm, such as nutrients, oxygen, or space. This could include contact-mediated competition, where a membrane protein or secretion system delivers toxins to non-sibling cells in close proximity [31]. Alternatively, B. velezensis 9D-6 may promote ISR
Table 2 Less common antimicrobial gene clusters present in $B$. velezensis strains

\begin{tabular}{|c|c|c|c|c|}
\hline Strain & Ladderane & Lantipeptide & Thiopeptide & Phosphonate \\
\hline YAU B9601-Y2 & & $\checkmark$ & & $\checkmark$ \\
\hline \multicolumn{5}{|l|}{ CC09 } \\
\hline \multicolumn{5}{|l|}{ UCMB5036 } \\
\hline \multicolumn{5}{|l|}{ SB1216 } \\
\hline \multicolumn{5}{|l|}{ UCMB5033 } \\
\hline \multicolumn{5}{|l|}{ TrigoCor1448 } \\
\hline 9D-6 & $\checkmark$ & $\checkmark$ & & \\
\hline AS43.3 & $\checkmark$ & & & \\
\hline G341 & & $\checkmark$ & & \\
\hline UCMB5113 & $\checkmark$ & $\checkmark$ & & \\
\hline JTYP2 & & $\checkmark$ & & \\
\hline sx01604 & & $\checkmark$ & & \\
\hline LS69 & & $\checkmark$ & & \\
\hline S3-1 & & $\checkmark$ & & \\
\hline CBMB205 & & $\checkmark$ & & \\
\hline \multicolumn{5}{|l|}{ YJ11-14 } \\
\hline \multicolumn{5}{|l|}{ SQR9 } \\
\hline GH1-13 & & $\checkmark$ & & \\
\hline D2-2 & & & $\checkmark$ & \\
\hline \multicolumn{5}{|l|}{ SYBC H47 } \\
\hline M75 & & $\checkmark$ & $\checkmark$ & \\
\hline \multicolumn{5}{|l|}{ JJ-D34 } \\
\hline NJN-6 & & $\checkmark$ & & \\
\hline B25 & & $\checkmark$ & $\checkmark$ & \\
\hline \multicolumn{5}{|l|}{ CAU B946 } \\
\hline$J S 25 R$ & & & & $\checkmark$ \\
\hline NAU-B3 & & & & $\checkmark$ \\
\hline 9912D & & $\checkmark$ & & \\
\hline
\end{tabular}

against $P$. syringae DC3000, a mechanism which may also involve surfactin [32] or butanediol, production of which by $B$. velezensis 9D-6 is inferred from the genome.

\section{Conclusions}

Here, we showed that $B$. velezensis 9D-6 exhibits, overall, a high degree of inhibition against phylogenetically diverse microbial pathogens. Its genome contains a unique complement of 13 gene clusters that are expected to participate in antimicrobial production, with $\left[\mathrm{Leu}^{7}\right]$ surfactins $\mathrm{C}_{14}$ and $\mathrm{C}_{15}$ confirmed as contributing at least to antibacterial activity in vitro. In addition, we found $B$. velezensis $9 \mathrm{D}-6$ is able to reduce root colonization by $P$. syringae DC3000, whose in vitro growth was not inhibited, demonstrating that B. velezensis 9D-6 can use additional mechanisms to control phytopathogens. $B$. velezensis 9D-6 is therefore a candidate biopesticide. The 
data presented here not only highlight the potential of $B$. velezensis 9D-6 as a biocontrol agent against phytopathogens, but also warrant further research and understanding of B. velezensis 9D-6, and may therefore contribute to future utilization of this strain.

\section{Methods}

\section{Isolation of $B$. velezensis 9D-6}

Soil samples were collected from Blizman potato fields in Norfolk County, Ontario, Canada in the summer of 2012. Over the previous three years, bio-organic fertilizer was added to the soil each spring in an effort toward natural remediation. In 2012 (the fourth year), $10.0 \mathrm{~g}$ of moist soil was collected, placed in $95 \mathrm{~mL}$ of sterile water, and shaken for $10 \mathrm{~min}$. Then, $1.0 \mathrm{~mL}$ of this suspension was transferred for serial dilution up to $10^{-10}$, and the dilutions were plated on tryptic soy agar (TSA) for $48 \mathrm{~h}$ at $28^{\circ} \mathrm{C}$ to attain single colonies. Permission for this research was obtained from the Canadian Food Inspection Agency (CFIA).

\section{In vitro antagonism assays against microbial pathogens}

Six-hundred bacterial strains were further screened for their ability to suppress phytopathogens under in vitro conditions. Antimicrobial discs were prepared by inoculating $0.5 \mathrm{~mm}$ discs of P8 Filter Paper (Thermo Fisher Scientific, Pittsburgh, PA, USA) with $50 \mu \mathrm{L}$ of $10^{9} \mathrm{CFU} / \mathrm{mL} B$. velezensis 9D-6 suspended in $0.85 \% \mathrm{NdaCl}$. To test inhibition of pathogenic bacteria, $100 \mu \mathrm{L}$ of each bacterial test strain at $10^{9} \mathrm{CFU} / \mathrm{mL}$ in $0.85 \% \mathrm{NaCl}$ were spread onto separate LB agar plates, and an antimicrobial disc containing $B$. velezensis 9D- 6 was placed in the centre of the plate. After two days incubation at $28^{\circ} \mathrm{C}$, zones of inhibition around the discs were recorded. Bacterial test strains were Bacillus cereus, Clavibacter michiganensis, Erwinia amylovora, Pantoea agglomerans, Pseudomonas syringae DC3000, Ralstonia solanacearum, Xanthomonas campestris, and Xanthomonas euvesicatoria.

To test inhibition of pathogenic eukaryotes, four plugs from each tested strain were evenly spaced at the peripheries of a potato dextrose agar plate, and an antimicrobial disc containing $B$. velezensis 9D-6 was placed in the centre of the plate. After one to two weeks of incubation (depending on the growth rate of the test strain) at room temperature, zones of inhibition around the discs were recorded. Eukaryotic test strains were Alternaria solani, Cochliobolus carbonum, Fusarium oxysporum, Fusarium solani, Gibberella pulicaris, Gibberella zeae, Monilinia fructicola, Pyrenochaeta terrestris, Pythium mamillatum, and Rhizoctonia solani.

\section{S rRNA sequencing and analysis}

Bacterial genomic DNA was used for PCR amplification of $16 \mathrm{~S}$ rRNA. For genomic DNA isolation, a single bacterial colony was inoculated into $2.5 \mathrm{ml}$ of LB broth and grown for $16 \mathrm{~h}$ at $30^{\circ} \mathrm{C}$ with shaking at $200 \mathrm{rpm}$. Cells were collected by centrifugation of $1.5 \mathrm{ml}$ culture at 13,000 rpm for $5 \mathrm{~min}$ and bacterial genomic DNA was isolated using GenElute Bacterial Genomic DNA Isolation kit (Sigma-Aldrich Co., St. Louis, MO, USA) in accordance with the manufacturer's protocol. PCR amplification of an approximately 1,500 base pair sequence of the bacterial 16S rDNA gene was performed with primers 8F (5'- AGAGTTTGATCCTGGCTCAG-3') and 1492R (5'-GGTTACCTTGTTACGACTT-3') [35]. Each $50 \mu \mathrm{L}$ PCR mixture contained 1.5 units Phusion High-Fidelity DNA Polymerase (Thermo Fisher Scientific Inc., Waltham, MA, USA), 1X PCR buffer, $2.0 \mathrm{mM}$ $\mathrm{MgCl} 2,200 \mu \mathrm{M}$ dNTPs, $2.5 \mu \mathrm{M}$ of each primer, $50 \mathrm{ng}$ of genomic DNA template, and ultrapure water (SigmaAldrich Co.). The cycle parameters were as follows: initial denaturation at $95^{\circ} \mathrm{C}$ for $5 \mathrm{~min}$, followed by 30 cycles of denaturation at $94{ }^{\circ} \mathrm{C}$ for $30 \mathrm{~s}$, annealing at $57^{\circ} \mathrm{C}$ for $45 \mathrm{~s}$, and extension at $72^{\circ} \mathrm{C}$ for $60 \mathrm{~s}$, with the final overall extension at $72{ }^{\circ} \mathrm{C}$ for $10 \mathrm{~min}$. The $16 \mathrm{~S}$ PCR products were purified by using QIAquick PCR Purification kit (Qiagen, Hilden, Germany) and sequenced with $8 \mathrm{~F}$ and $1492 \mathrm{R}$ primers on a 3730 DNA Analyzer (Thermo Fisher Scientific Inc.) at Agriculture and Agri-Food Canada (London, Ontario, Canada). The 16S rRNA gene fragment was compared with the NCBI nucleotide database using Blastn to determine the closest taxonomic relatives.

\section{Phylogenetic tree construction}

A phylogenetic tree was constructed based on RNA polymerase $\beta$ subunit (rpo) gene sequences [9] obtained from the genome sequence (see below) to estimate the evolutionary position of B. velezensis 9D-6 relative to other B. velezensis strains. The Rpo protein sequence of Bacillus subtilis subspecies subtilis strain 168 (GenBank Accession NP_387988) was used as a query for translated BLAST (tblastn) against $B$. velezensis gene sequences in the NCBI database. In total, $28 B$. velezensis rpo sequences were copied and aligned with rpo from $B$. subtilis subtilis 168 using WebPRANK software [36]. The type strains of B. velezensis are NRRL B-41580 and KCTC 13012 [37], but neither of their genome sequences are complete, and they were therefore excluded from the analysis. Phylogenetic trees were constructed using MrBayes v.3.2 [38] with the generalised time reversible (GTR) substitution model and default parameters for run length and frequencies. The B. subtilis subtilis 168 rpo was designated as an outgroup. Following analysis, the standard deviation of spilt frequencies was 0.006566 and the potential scale reduction factor (PSRF) was 1.000 or 1.001 for all factors. The majority-rule consensus tree was visualized using TreeGraph2 [39]. 
Extraction and identification of antimicrobial compounds To identify potential antimicrobial compounds produced by $B$. velezensis 9D-6, metabolites were isolated from a liquid LB culture grown at $28^{\circ} \mathrm{C}$ for $72 \mathrm{~h}$ by ethyl acetate, liquid/liquid extraction. The extract was dried and resuspended in acetonitrile. After verifying the antibacterial and antifungal activity of the crude solution, compounds were separated into 22 fractions using a C18 reverse-phase high performance liquid chromatographer on a 1260 Infinity Series (Agilent Technologies, Santa Clara, CA, USA) eluted using an acetonitrile-water gradient with $0.1 \%$ formic acid.

Fractions were each tested in duplicate for their antibacterial activity against C. michiganensis. Each antimicrobial disc was prepared by adding $50 \mu \mathrm{L}$ of a fraction to a $0.5 \mathrm{~mm}$ disc of P8 Filter Paper (Thermo Fisher Scientific, Pittsburgh, PA, USA), which was then placed onto an LB agar plate spread with $100 \mu \mathrm{L}$ of 109 $\mathrm{CFU} / \mathrm{mL}$ C. michiganensis in $0.85 \% \mathrm{NaCl}$. Controls used acetonitrile in place of the metabolite fraction.

Fractions demonstrating antibacterial effects were individually analyzed using ultraviolet-visible (UV-vis) spectroscopy at $210 \mathrm{~nm}$ and $254 \mathrm{~nm}$ to identify UV-active compounds. These compounds were isolated and tested in a final in vitro antibacterial plate assay against $C$. michiganensis. The compounds of bioactive fractions were characterized by high resolution LC-MS/ MS using a Q-Exactive Quadrupole-Orbitrap Mass Spectrometry (Thermo Fisher Scientific, Waltham, MA, USA). Full MS and MS/MS spectra were analyzed manually with XCalibur software (Thermo Fisher Scientific, Waltham, MA, USA). The full MS data was used to identify possible molecular formula $(<3 \mathrm{ppm})$. Formulas were than searched against the AntiBase 2012 Natural Compound Identifier database [40] to identify purified compounds. When possible, the MS/MS spectra were used for de novo sequencing of peptide containing compounds to confirm possible Antibase identified compounds.

The surfactin fraction was then tested for activity against $P$. syringae DC3000 and C. carbonum. Discs were inoculated with $50 \mu \mathrm{L}$ of the fraction at concentrations of $10 \mathrm{mg} / \mathrm{mL}, 5 \mathrm{mg} / \mathrm{mL}, 2.5 \mathrm{mg} / \mathrm{mL}$, and $1 \mathrm{mg} / \mathrm{mL}$. Discs were then placed onto LB agar plates that were either spread with $P$. syringae DC3000 or contained a central agar plug of C. carbonum.

\section{In vivo biocontrol}

To determine whether alternative control mechanisms (such as induced systemic resistance) might be elicited by $B$. velezensis $9 \mathrm{D}-6$, we tested its ability to reduce root colonization by $P$. syringae DC3000, a Gram-negative bacterium whose growth in vitro was not inhibited by $B$. velezensis 9D-6. P. syringae DC3000 was labeled using a red fluorescent protein (RFP) reporter gene construct based on the plasmid pME6010 [41, 42], and used to inoculate Arabidopsis thaliana (L.) Heynh seedlings in hydroponic medium $\left(2.5 \times 10^{5} \mathrm{CFU} / \mathrm{mL}\right)$, with or without $B$. velezensis 9D-6 $\left(2.5 \times 10^{6} \mathrm{CFU} / \mathrm{mL}\right)$, as previously described [43]. The A. thaliana (L.) Heynh seeds were obtained from the Arabidopsis Biological Resource Center (Columbus, OH, U.S.A) and grown as previously described [43].

After seven days, A. thaliana roots were removed from the medium, rinsed in ultrapure water to remove loosely bound material, and attachment by labeled $P$. syringae DC3000 was imaged using a DMIRE2 inverted microscope with confocal laser scanner (Leica Microsystems $\mathrm{GmbH}$, Wetzlar, Germany). Samples were excited using a helium-neon 543/594 nm laser, and emission was detected at $590-630 \mathrm{~nm}$ under a $63 \mathrm{x}$ water immersion objective with a numerical aperture of 1.4.

\section{Genome sequencing and annotation}

Following isolation from potato field soil of Norfolk County, Ontario, Canada, a single colony of $B$. velezensis 9D-6 was grown for $48 \mathrm{~h}$ in $3 \mathrm{~mL}$ of lysogeny broth (LB) at $28^{\circ} \mathrm{C}$ and $60 \mathrm{rpm}$ in a TC-7 drum rotor (New Brunswick Scientific Co., Enfield, CT, USA). Genomic DNA was isolated from $1.5 \mathrm{~mL}$ of the culture using the GenElute Bacterial Genomic DNA kit (Sigma-Aldrich Co., St. Louis, MO, USA) according to the manufacturer's protocol for Gram positive bacteria, with the exception that DNA was eluted in UltraPure DNase/RNase-free distilled water (Thermo Fisher Scientific Corp., Waltham, MA, USA). DNA quality was assessed by agarose gel electrophoresis.

Genomic DNA was sequenced at AGCT Inc. (Wheeling, IL, USA) using the MiSeq next generation sequencing platform (Illumina Inc., San Diego, CA, USA). Libraries were constructed using the NexteraXT DNA sample preparation kit (Illumina Inc., San Diego, CA, USA) with a target average insert size of 500-600 bp. Sequencing generated 5,453,964 raw read pairs of $2 \times 150$ bp read length on average. Adaptor sequences, low quality sequences, and short reads were filtered out using BaseSpace (Illumina Inc., San Diego, CA, USA), Trim Galore (Babraham Bioinformatics, Babraham, UK), and Sickle [44]. The remaining 4,722,973 trimmed read pairs were assembled de novo and scaffolded with SPAdes v. 3.50 [45] into 47 contigs with an $\mathrm{N}_{50}$ of $507 \mathrm{~kb}$ spanning 100x coverage.

The draft genome was aligned with test reference genomes, including that of B. velezensis G341 (GenBank Accession CP011686), using the Mauve Multiple Genome Alignment tool [46] version 2.4.0 to generate a preliminary chromosome map. Primers were designed based on the contig orientations suggested by the 
chromosomal map, and connections were confirmed by Sanger sequencing of PCR products followed by alignment with the draft genome using SeqMan Pro (DNASTAR Inc., Madison, WI, USA) [47]. All gaps were closed with one of two repeat sequences; one containing a transposon region and one containing an rDNA operon sequence. After closure and validation of gaps between draft contigs, the final completed genome was assembled into a single $3.96 \mathrm{Mb}$ chromosome using the largest 20 contigs. The remaining 27 contigs were identified as redundant fragments.

Numbers of genes (rRNA genes, protein coding genes, pseudogenes) were predicted on the DOE-JGI Microbial Genome Annotation Pipeline (MGAP v.4) [48]. In silico DNA-DNA hybridization (is DDH) was performed via the GGDC web server (http://ggdc.gbdp.org) using formula 2 [49]. Secondary metabolite clusters were identified using both MGAP v.4 and antiSMASH3.0 [50]. The genome was also mined in silico using target amino acid sequences from closely related species from the UniProtKB sequence database [51] and comparing them to translated draft genome nucleotide data using tBLASTn.

\section{Additional files}

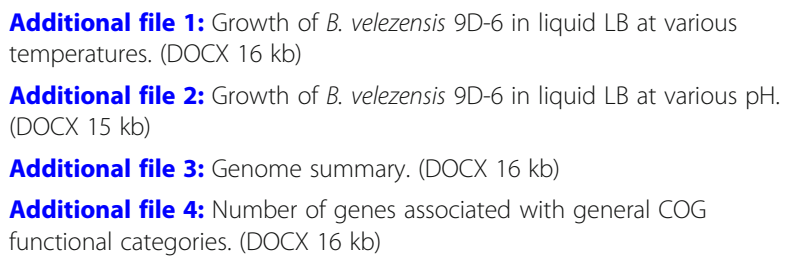

\begin{abstract}
Abbreviations
Bt: Bacillus thuringiensis; CFU: colony forming unit; GTR: generalised time reversible model of nucleic acid substitution; ISR: induced systemic resistance; nrps: nonribosomal peptide synthetase; PGPB: plant growth promoting bacterium; PSRF: potential scale reduction factor; RFP: red fluorescent protein; t2pks: Type II polyketide synthase; t3pks: Type III polyketide synthase; Tat: twin-arginine translocation; transatpks: transacyltransferase modular polyketide synthase
\end{abstract}

\section{Acknowledgements}

We thank Alexander W. Eastman, Filip Zekic, Niki Bennett (OGVG) and Dr. Erin Azzopardi (Mitacs) for useful discussions.

\section{Funding}

This work was supported by Agriculture and Agri-Food Canada Growing ForwardII [project J-001332 and project J-001589]; Natural Sciences and Engineering Research Council of Canada (NSERC) [Discovery grant RGPIN-2015-06052]; Ontario Greenhouse Vegetable Growers (OGVG) and Mitacs-Accelerate [Fund IT07941Yuan_OGVG]. The funders had no role in the design of the study or the collection, analysis, and interpretation of data.

\section{Availability of data and materials}

The datasets generated and analysed during the current study are available in the GenBank repository, https://www.ncbi.n/m.nih.gov/nuccore/CP020805, or included in this published article and its supplementary information files.

\section{Authors' contributions}

ENG contributed to genome sequencing, and completed the genome. ENG and BW performed in vivo experiments. JM and ENG drafted the manuscript. $\mathrm{JM}$ and $\mathrm{MH}$ contributed to the analysis and interpretation of data. TM and JR performed chemical extractions and surfactin identification. OS contributed to genome sequencing. ZCY conceived of the study, designed the experiments, and critically revised the manuscript. All authors read and approved the final manuscript.

\section{Ethics approval and consent to participate}

Not applicable.

\section{Consent for publication}

Not applicable.

\section{Competing interests}

The authors declare that they have no competing interests.

\section{Publisher's Note}

Springer Nature remains neutral with regard to jurisdictional claims in published maps and institutional affiliations.

Received: 21 August 2018 Accepted: 25 December 2018

Published online: 08 January 2019

\section{References}

1. Aktar W, Sengupta D, Chowdhury A. Impact of pesticides use in agriculture: their benefits and hazards. Interdiscip Toxicol. 2009;2:1-12.

2. Vessey JK. Plant growth promoting rhizobacteria as biofertilizers. Plant Soil. 2003;255:571-86.

3. Verschuere L, Rombaut G, Sorgeloos P, Verstraete W. Probiotic bacteria as biological control agents in aquaculture. Microbiol Mol Biol Rev. 2000;64: 655-71.

4. Gong AD, Li HP, Yuan QS, Song XS, Yao W, He WJ, et al. Antagonistic mechanism of iturin a and plipastatin a from Bacillus amyloliquefaciens S763 from wheat spikes against Fusarium graminearum. PLoS One. 2015;10: e0116871.

5. Compant S, Duffy B, Nowak J, Clément C, Barka EA. Use of plant growthpromoting bacteria for biocontrol of plant diseases: principles, mechanisms of action, and future prospects. Appl Environ Microbiol. 2005;71(9):4951-9.

6. Ruiz-García C, Béjar V, Martínez-Checa F, Llamas I, Quesada E. Bacillus velezensis sp. nov., a surfactant-producing bacterium isolated from the river Vélez in Málaga, southern Spain. Int J Syst Evol Micr. 2005;55:191-5.

7. Palazzini JM, Dunlap CA, Bowman MJ, Chulze SN. Bacillus velezensis RC 218 as a biocontrol agent to reduce Fusarium head blight and deoxynivalenol accumulation: genome sequencing and secondary metabolite cluster profiles. Microbiol Res. 2016;192:30-6.

8. Gao Z, Zhang B, Liu H, Han J, Zhang Y. Identification of endophytic Bacillus velezensis ZSY-1 strain and antifungal activity of its volatile compounds against Alternaria solani and Botrytis cinerea. Biol Control. 2017;105:27-39.

9. Case RJ, Boucher Y, Dahllöf I, Holmström C, Doolittle WF, Kjelleberg S. Use of $16 \mathrm{~S}$ rRNA and rpoB genes as molecular markers for microbial ecology studies. Appl Environ Microbiol. 2007;73:278-88.

10. Daferera DJ, Ziogas BN, Polissiou MG. The effectiveness of plant essential oils on the growth of Botrytis cinerea, Fusarium sp. and Clavibacter michiganensis subsp. michiganensis. Crop Prot 2003; 22:39-44.

11. Nandi M, MacDonald J, Liu P, Weselowski B, Yuan ZC. Clavibacter michiganensis ssp. michiganensis: bacterial canker of tomato, molecular interactions and disease management. Mol Plant Pathol. 2018;19:2036-50.

12. Jasim B, Sreelakshmi S, Mathew J, Radhakrishnan EK. Identification of endophytic Bacillus mojavensis with highly specialized broad spectrum antibacterial activity. 3 Biotech. 2016;6:187.

13. Cai XC, Liu CH, Wang BT, Xue YR. Genomic and metabolic traits endow Bacillus velezensis CC09 with a potential biocontrol agent in control of wheat powdery mildew disease. Microbiol Res. 2017;196:89-94.

14. Fan B, Blom J, Klenk HP, Borriss R. Bacillus amyloliquefaciens, Bacillus velezensis, and Bacillus siamensis Form an "Operational Group B. amyloliquefaciens" within the B. subtilis Species Complex. Front Microbiol. 2017;8:22. 
15. van Zyl LJ, Matobole R, Nsole Biteghe FA, Klein T, Kirby B, Trindade M Draft genome sequences of three Bacillus species from south African marine sponges. Genome Announc. 2016;4:e00143-16.

16. Lee $H$, Kim HY. Lantibiotics, class I bacteriocins from the genus Bacillus. J Microbiol Biotechnol. 2011;21:229-35.

17. Van der Donk WA, Nair SK. Structure and mechanism of lanthipeptide biosynthetic enzymes. Curr Opin Struc Biol. 2014;29:58-66.

18. López-Lara IM, Geiger O. Bacterial lipid diversity. Biochim Biophys Acta. 1862;2017:1287-99.

19. Cimermancic P, Medema MH, Claesen J, Kurita K, Wieland Brown LC, Mavrommatis $K$, et al. Insights into secondary metabolism from a global analysis of prokaryotic biosynthetic gene clusters. Cell. 2014;158:412-21.

20. Schöner TA, Gassel S, Osawa A, Tobias NJ, Okuno Y, Sakakibara Y, et al. Aryl polyenes, a highly abundant class of bacterial natural products, are functionally related to antioxidative carotenoids. Chembiochem. 2016;17: 247-53.

21. Ryu CM1, Farag MA, Hu CH, Reddy MS, Kloepper JW, Paré PW. Bacterial volatiles induce systemic resistance in Arabidopsis. Plant Physiol. 2004;134: 1017-26.

22. Palmer $\mathrm{T}$, Berks BC. The twin-arginine translocation (tat) protein export pathway. Nat Rev Microbiol. 2012;10:483-96.

23. Denks K, Vogt A, Sachelaru I, Petriman NA, Kudva R, Koch HG. The sec translocon mediated protein transport in prokaryotes and eukaryotes. Mol Membr Biol. 2014;31:58-84

24. Peypoux F, Michel G. Controlled biosynthesis of Val7- and Leu7-surfactins. Appl Microbiol Biot. 1992;36:515-7.

25. Li YM, Haddad NIA, Yang SZ, Mu BZ. Variants of lipopeptides produced by Bacillus licheniformis HSN221 in different medium components evaluated by a rapid method ESI-MS. Int J Pept Res Ther. 2008;14: 229-35.

26. Baumgart $R$, Kluge B, Ullrich $C$, Vater J, Ziessow D. Identification of amino acid substitutions in the lipopeptide surfactin using 2D NMR spectroscopy. Biochem Biophys Res Commun. 1991;177:998-1005.

27. Sarwar A, Hassan MN, Imran M, lqbal M, Majeed S, Brader G, Sessitsch A, Hafeez FY. Biocontrol activity of surfactin a purified from Bacillus NH-100 and NH-217 against rice bakanae disease. Microbiol Res. 2018;209:1-13.

28. Goussous SA, Casford MTL, Murphy AC, Salmond GPC, Leeper FJ, Davies PB. Structure of the fundamental lipopeptide surfactin at the air/water interface investigated by sum frequency generation spectroscopy. J Phys Chem B. 2017;121:5072-7

29. Hamley IW. Lipopeptides: from self-assembly to bioactivity. Chem Commun. 2015:51:8574-83.

30. Zhao H, Shao D, Jiang C, Shi J, Li Q, Huang Q, Rajoka MSR, Yang H, Jin Biological activity of lipopeptides from Bacillus. Appl Microbiol Biotechnol 2017;101:5951-5960.

31. Stubbendieck RM, Straight PD. Multifaceted interfaces of bacterial competition. J Bacteriol. 2016;198:2145-55

32. Cawoy H, Mariutto M, Henry G, Fisher C, Vasilyeva N, Thonart P, Dommes J, Ongena M. Plant defense stimulation by natural isolates of Bacillus depends on efficient surfactin production. Mol Plant Microbe In. 2014;27:87-100.

33. Paraszkiewicz K, Bernat $P$, Siewiera P, Moryl M, Sas-Paszt L, Trzciński $P$, Jałowiecki L, Płaza G. Agricultural potential of rhizospheric Bacillus subtilis strains exhibiting varied efficiency of surfactin production. Sci HorticAmsterdam. 2017;225:802-9.

34. Kearns DB. A field guide to bacterial swarming motility. Nat Rev Microbiol. 2010;8:634-44.

35. Turner S, Pryer KM, Miao VP, Palmer JD. Investigating deep phylogenetic relationships among cyanobacteria and plastids by small subunit rRNA sequence analysis. J Eukaryot Microbiol. 1999;46:327-38.

36. Löytynoja A, Goldman N. WebPRANK: a phylogeny-aware multiple sequence aligner with interactive alignment browser. BMC Bioinformatics. 2010;11:579.

37. Dunlap CA, Kim SJ, Kwon SW, Rooney AP. Bacillus velezensis is not a later heterotypic synonym of Bacillus amyloliquefaciens; Bacillus methylotrophicus, Bacillus amyloliquefaciens subsp plantarum and 'Bacillus oryzicola' are later heterotypic synonyms of Bacillus velezensis based on phylogenomics. Int J Syst Evol Microbiol. 2016;66:1212-7.

38. Ronquist F, Teslenko M, van der Mark P, Ayres D, Darling A, Höhna S, et al. MrBayes 3.2: efficient Bayesian phylogenetic inference and model choice across a large model space. Syst Biol. 2012;61:539-42.

39. Stöver BC, Müller KF. TreeGraph 2: combining and visualizing evidence from different phylogenetic analyses. BMC Bioinformatics. 2010;11:7.
40. Laatsch $\mathrm{H}$. Antibase version 4.0: the natural compound identifier. Wiley-VCH Verlag GmbH \& Co. KGaA, 2012.

41. Heeb S, Itoh Y, Nishijyo T, Schnider U, Keel C, Wade J, Walsh U, O'Gara F, Haas D. Small, stable shuttle vectors based on the minimal pVS1 replicon for use in gram-negative, plant associated bacteria. Mol Plant-Microbe Interact. 2000;13:232-7.

42. Bloemberg GV, Wijfjes AH, Lamers GE, Stuurman N, Lugtenberg BJ. Simultaneous imaging of Pseudomonas fluorescens WCS365 populations expressing three different autofluorescent proteins in the rhizosphere: new perspectives for studying microbial communities. Mol Plant-Microbe Interact. 2000;13:1170-6.

43. Nathoo N, Bernards MA, MacDonald J, Yuan ZC. A hydroponic co-cultivation system for simultaneous and systematic analysis of plant-microbe molecular interactions and signaling. JOVE-J Vis Exp. 2017;125:e55955.

44. Joshi NA, Fass JN. Sickle: A sliding-window, adaptive, quality-based trimming tool for FastQ files. GitHub. 2011. https://github.com/najoshi/ sickle. Accessed 1 June 2017.

45. Bankevich A, Nurk S, Antipov D, Gurevich AA, Dvorkin M, Kulikov AS, et al. SPAdes: a new genome assembly algorithm and its applications to singlecell sequencing. J Comput Biol. 2012;19:455-77.

46. Darling AC, Mau B, Blattner FR, Perna NT. Mauve: multiple alignment of conserved genomic sequence with rearrangements. Genome Res. 2004;14: 1394-403.

47. Burland TG. DNASTAR's Lasergene sequence analysis software. In: Misener S, Krawetz SA, editors. Bioinformatics methods and protocols. Totowa, NJ, USA Humana press Inc; 1999. p. 71-91.

48. Markowitz VM, Chen I-MA, Palaniappan K, Chu K, Szeto E, Grechkin Y, et al. IMG: the integrated microbial genomes database and comparative analysis system. Nucleic Acids Res. 2012;40:D115-22.

49. Auch AF, Klenk HP, Göker M. Standard operating procedure for calculating genome-to-genome distances based on high-scoring segment pairs. Stand Genomic Sci. 2010;2:142-8.

50. Weber T, Blin K, Duddela S, Krug D, Kim H, Bruccoleri R, et al. AntiSMASH 3.0 - a comprehensive resource for the genome mining ofbiosynthetic gene clusters. Nucleic Acids Res. 2015;43:W237-43.

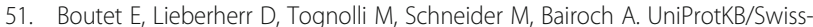
Prot: the manually annotated section of the UniProt KnowledgeBase. In: Edwards D, editor. Plant bioinformatics: methods and protocols. Totowa, NJ, USA: Humana press Inc; 2007. p. 89-112.

52. Lund T, De Buyser ML, Granum PE. A new cytotoxin from Bacillus cereus that may cause necrotic enteritis. Molecular Microbial. 2000;8:254-61.

53. Vanneste JL. Fire blight: the disease and its causative agent, Erwinia amylovora. 2000: CABI.

54. Dutkiewicz J, Mackiewicz B, Kinga-Lemieszek M, Golec M, Milanowski J. Pantoea agglomerans: a mysterious bacterium of evil and good. Part III. Deleterious effects: infections of humans, animals and plants. Ann Agric Environ Med. 2016;23:197-205.

55. Wei CF, Kvitko BH, Shimizu R, Crabill E, Alfano JR, Lin NC, Martin GB, Huang HC, Collmer A. A Pseudomonas syringae pv. Tomato DC3000 mutant lacking the type III effector HopQ1-1 is able to cause disease in the model plant Nicotiana benthamiana. Plant J. 2007:51:32-46.

56. Salanoubat M, Genin S, Artiguenave F, Gouzy J, Mangenot S, Arlat M, Billault A, Brottier P, Camus JC, Cattolico L, Chandler M, Choisne N, Claudel-Renard C, Cunnac S, Demange N, Gaspin C, Lavie M, Moisan A, Robert C, Saurin W, Schiex T, Siguier $P$, Thébault $P$, Whalen $M$, Wincker $P$, Levy $M$, Weissenbach J, Boucher CA. Genome sequence of the plant pathogen Ralstonia solanacearum. Nature. 2002;415:497-502.

57. Vicente JG, Holub EB. Xanthomonas campestris pv. campestris (cause of black rot of crucifers) in the genomic era is still a worldwide threat to brassica crops. Mol Plant Pathol. 2013;14:2-18.

58. Fontenelle ADB, Guzzo SD, Lucon CMM, Harakava R. Growth promotion and induction of resistance in tomato plant against Xanthomonas euvesicatoria and Alternaria solani by Trichoderma spp. Crop Prot. 2011;30:1492-500.

59. Manamgoda DS, Cai L, Bahkali AH, Chukeatirote E, Hyde KD. Cochliobolus: an overview and current status of species. Fungal Divers. 2011;51:3-42.

60. Fravel D, Olivain C, Alabouvette C. Fusarium oxysporum and its biocontrol. New Phytol. 2003;157:493-502.

61. Zhang N, O'Donnell K, Sutton DA, Nalim FA, Summerbell RC, Padhye AA, Geiser DM. Members of the Fusarium solani species complex that cause infections in both humans and plants are common in the environment. J Clin Microbiol. 2006:44:2186-90. 
62. Mecteau MR, Arul J, Tweddell RJ. Effect of organic and inorganic salts on the growth and development of Fusarium sambucinum, a causal agent of potato dry rot. Mycol Res. 2002;106:688-96.

63. Sutton J. Epidemiology of wheat head blight and maize ear rot caused by Fusarium graminearum. Can J Plant Pathol. 1982;4:195-209.

64. Munda A, Viršček-Marn M. First report of brown rot caused by Monilinia fructicola affecting peach orchards in Slovenia. Plant Dis. 2010;94:1166.

65. Porter I, Merriman P, Keane P. Integrated control of pink root (Pyrenochaeta terrestris) of onions by dazomet and soil solarization. Crop and Pasture Sci. 1989;40:861-9.

66. Parmeter JR. Rhizoctonia solani, biology and pathology. 1970: Univ of California Press.

67. Madden L, Pennypacker S, MacNab A. FAST, a forecast system for Alternaria solani on tomato. Phytopathology. 1978;68:1354-8.

68. Botha WJ, Coetzer RLJ. Species of Pythium associated with root-rot of vegetables in South Africa. S Afr J Bot. 1996;62:196-203.

69. Matoba Y, Kondo N, Akino S, Kodama F, Naito S, Ebe S. Identification and pathogenicity of Pythium species causing damping-off of kidney bean. J Gen Plant Pathol. 2008;74:81-5.

Ready to submit your research? Choose BMC and benefit from:

- fast, convenient online submission

- thorough peer review by experienced researchers in your field

- rapid publication on acceptance

- support for research data, including large and complex data types

- gold Open Access which fosters wider collaboration and increased citations

- maximum visibility for your research: over $100 \mathrm{M}$ website views per year

At $\mathrm{BMC}$, research is always in progress.

Learn more biomedcentral.com/submissions 